\title{
ENSAIOS IZOD DE COMPÓSITOS DE MATRIZ EPÓXI REFORÇADO COM TECIDO DE RAMI *
}

\author{
Noan Tonini SImonassi ${ }^{1}$ \\ Sergio Neves Monteiro ${ }^{2}$ \\ Ana Carolina Marotti Dias ${ }^{3}$ \\ Davi Gomes de Albuquerque ${ }^{3}$ \\ Marlon David Palozi ${ }^{3}$ \\ Mateus Caracas Veras ${ }^{3}$ \\ Matheus Pereira de Souza ${ }^{3}$ \\ Viviane Silva Souza Freitas ${ }^{3}$
}

\section{Resumo}

Fibras naturais lignocelulósicas, como piaçava, curauá, juta, rami, dentre outras, estão sendo empregadas como reforço de compósitos de matriz polimérica para melhoramento de propriedades mecânicas desses. Sendo assim, o presente trabalho tem por objetivo a investigação da resistência ao impacto de compósitos com matriz epoxídica reforçados por tecido de fibras de rami, fibra extraída do caule da planta de rami, nativa da Ásia Oriental. Para tanto, ensaios de impacto Izod foram realizados e mostraram que a incorporação dessas fibras incrementa a absorção de energia de impacto dos compósitos e que a resistência ao impacto aumenta com a quantidade relativa de fibra reforçando o compósito. Este desempenho pode ser associado à dificuldade de ruptura imposta pelas fibras bem como ao tipo de trincas resultantes da interação tecido/matriz.

Palavras-chave: Izod; Tecido de rami; Epóxi; Compósitos.

\section{IZOD TESTS IN EPOXY MATRIX COMPOSITES REINFORCED WITH RAMIE}

\section{FABRIC}

\section{Abstract}

Natural lignocellulosic fibers such as palm fiber, curaua, jute, ramie, among others, are employed as reinforcement in polymer matrix composites to improve the mechanical properties. The present study aims to investigate the impact resistance of composites with epoxy matrix reinforced by ramie fiber fabric extracted from the ramie plant stem, native to East Asia. Therefore, Izod impact tests were conducted and showed that the incorporation of these fibers increases the impact energy absorption of the composite, and the impact resistance increases with the relative amount of fiber reinforcing composite. This performance may be associated with difficulty to break imposed by the fibers as well as the type of cracks resulting from the interaction tissue / matrix

Keywords: Izod; Ramie fabric; Epoxy; Composites

1 Engenheiro Metalurgista, Estudante de Mestrado, Laboratório de fibras Naturais, Instituto Militar de Engenharia (IME), Rio de Janeiro, Brasil.

2 Engenheiro de Ciências dos Materiais, PhD, Professor titular, Laboratório de fibras Naturais, Instituto Militar de Engenharia (IME), Rio de Janeiro, Brasil.

3 Estudante de engenharia, Instituto Militar de Engenharia (IME), Rio de Janeiro, Brasil. 


\section{INTRODUÇÃO}

O uso de fibras naturais pelo homem esta presente desde os mais antigos registros históricos. Eram extraídas e utilizadas sem muito processamento na fabricação de utensílios domésticos como cestos e sacos, de cordas e posteriormente de tecidos e de tapetes. Entretanto, com o advento da pesquisa científica e principalmente a revolução industrial, a sociedade do século $X X$ passou a utilizar cada vez mais produtos industrializados, como os plásticos em geral, em detrimento das fibras naturais ${ }^{(1)}$. Além disso, as fibras sintéticas, como as fibras de vidro, de carbono e aramida, passaram a integrar praticamente todos os segmentos tecnológicos. Assim, surgiram dois problemas: a exploração excessiva de recursos não renováveis e a produção de resíduos não degradáveis. Anualmente, são consumidos no mundo 32 bilhões de toneladas de minerais (2) e foram produzidos, em 2012 passado, 1,3 bilhões de toneladas de lixo ${ }^{(3)}$.

O desenvolvimento da moderna sociedade está atrelado a sua capacidade de produzir e utilizar novos materiais. Os materiais recicláveis e biodegradáveis que não eram tão importantes no passado tornaram-se decisivos atualmente em função de paradigmas ambientais (4). Nesse contexto, surgiram várias pesquisas para a substituição de fibras sintéticas pelas fibras naturais, em especial as compostas a base de celulose e lignina, que oferecem vantagens sociais, econômicas, ambientais e tecnológicas $(5,6,7)$. Já no contexto nacional, verifica-se que a produção de fibras sintéticas é baixíssima devido ao pequeno número de patentes e à baixa produção industrial em relação ao consumo interno, fato que fica evidente no caso da fibra de carbono ${ }^{(8)}$. Esse fato cria um cenário propício para o estudo de fibras naturais, impulsionando o desenvolvimento e pesquisa na área.

As fibras naturais lignocelulósicas são, em sua maioria, fibras longas e possuem como principal característica estrutural cadeias poliméricas longas de celulose ligadas por lignina, a qual se deve a boa resistência mecânica longitudinal (6). O uso dessas fibras como reforço em compósitos de matriz polimérica tem se mostrado muito promissor, por sua baixa densidade e baixo custo de produção aliado a boas propriedades mecânicas. Alguns compósitos, como o de matriz epóxi reforçado com fibra de sisal, possuem resistência a impacto comparável a compósitos reforçados com fibra de vidro ${ }^{(9)}$. Além disso, há a redução do impacto ambiental tanto na obtenção da matéria prima, dada a quantidade de fibras já conhecidas e disponíveis, quanto no descarte do material ${ }^{(10)}$.

No presente artigo destaca-se a utilização de fibras naturais de rami, comumente aplicada como forrageira pela pecuária e empregada pela indústria têxtil na fabricação de tecidos utilizados em diversos fins, como roupas, decorações de interiores e até mesmo velame de paraquedas ${ }^{(11,12)}$ como material de engenharia. Por ser uma fibra natural, agrega todas as vantagens já destacadas, porém seu uso como reforço em materiais compósitos ainda não é difundido.

O rami (Boehmeria nivea), conhecido comercialmente como grama da China, ilustrado na Fig.1, é originário do sudeste asiático e produz fibras que podem ser 
extraídas do floema da planta. A partir destas fibras foi produzido o tecido que reforçará as placas de matriz epoxídica.
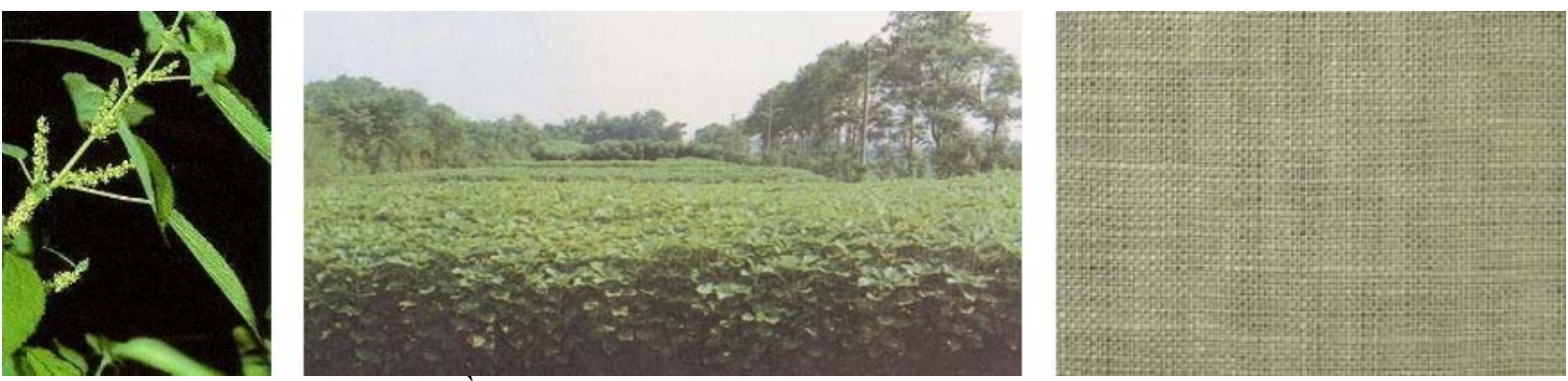

Figura 1: Ilustrações do rami. À esquerda, a Boehmeria nivea; no centro, a plantação; e à direita, o tecido de rami. (Foto de Swicofil).

Com base no exposto, esse trabalho tem como objetivo avaliar a resistência ao impacto, a partir de ensaios Izod, representado na Fig. $2^{(12)}$, de corpos de prova de matriz epóxi com diferentes quantidades de reforço de fibras de tecido de rami. É válido ressaltar que, na prática, o teste de Izod simula melhor a situação real de um componente fixo no sistema ${ }^{(12)}$.

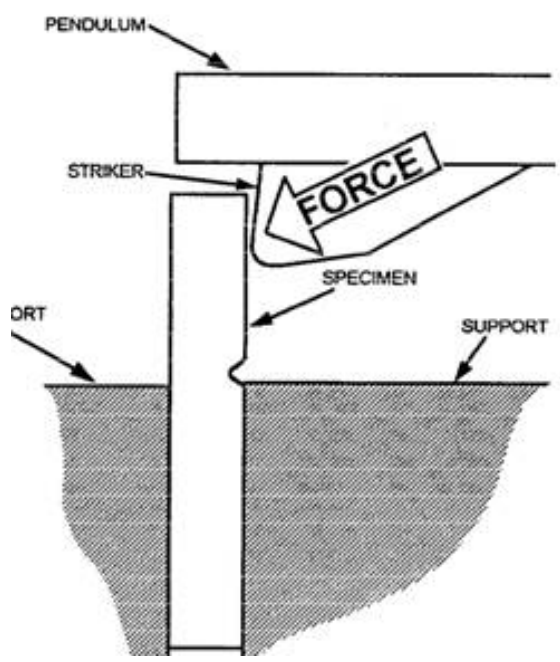

Figura 2: Teste de impacto Izod.

\section{MATERIAIS E MÉTODOS}

O tecido de rami utilizado foi comprado. Após um processo de limpeza e secagem em estufa a $60^{\circ} \mathrm{C}$ por $24 \mathrm{~h}$, o tecido foi cortado em formas retangulares iguais de modo que suas dimensões possuíssem aproximadamente o tamanho de um molde retangular de aço com dimensões 150 x 120 mm, apresentado na Fig. 3. 

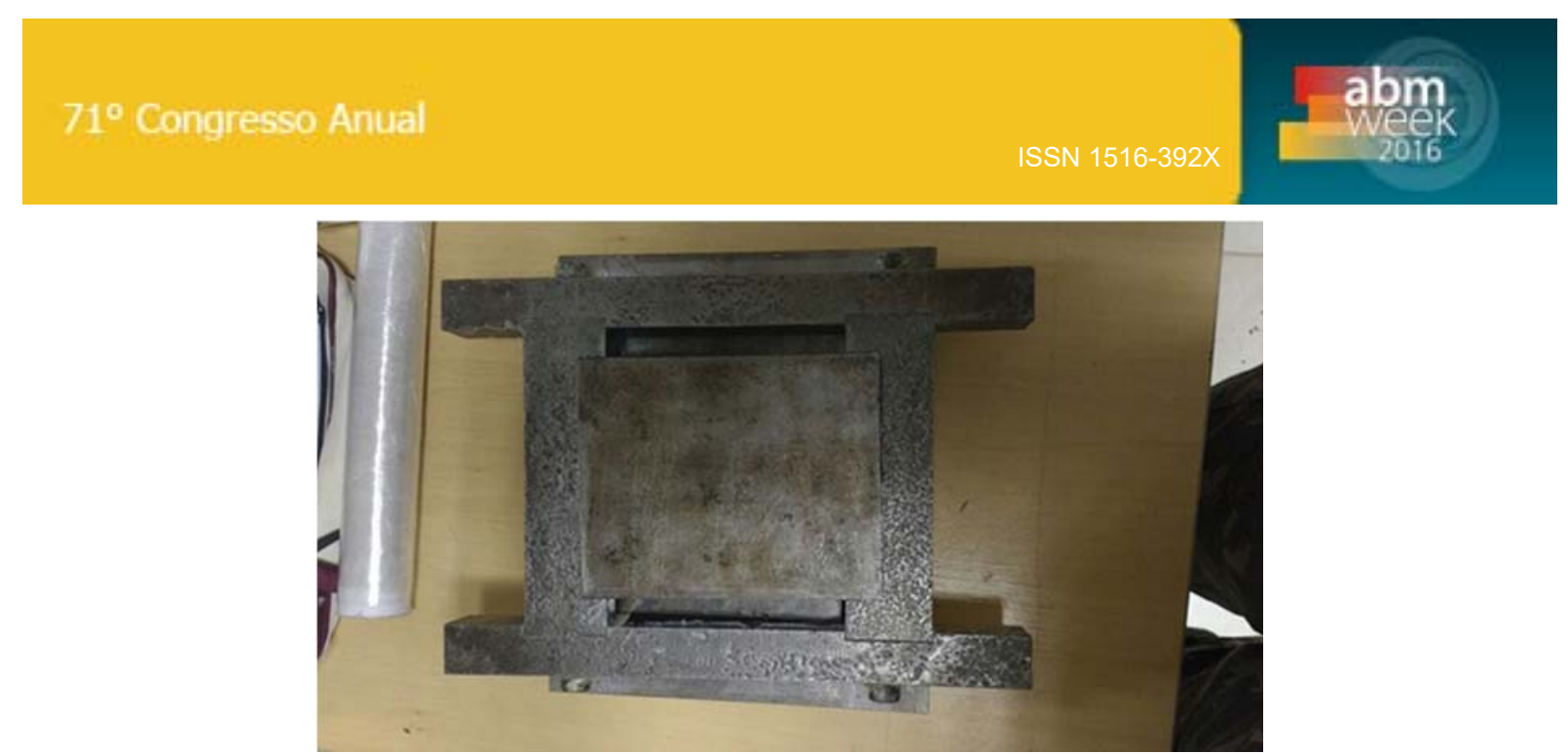

Figura 3: Matriz a ser empregada para compactação dos corpos de prova.

Primeiramente, foi necessária a medição da densidade do tecido de rami. Para tanto, foram feitas duas placas: uma de resina pura e uma utilizando a resina como matriz, acrescida de cortes do tecido (Fig. 4). A resina epóxi preparada é do tipo éter diglicidílico do bisfenol-A (DGEBA) misturada ao endurecedor trietileno tetramina (TETA) na proporção correspondente a 13 partes de endurecedor por 100 partes de resina. A primeira, foi deixada curar no molde por um período de $24 \mathrm{~h}$ à temperatura ambiente, como garantia de que os gases produzidos durante a reação de polimerização fossem liberados, diminuindo, assim, a incidência de aparecimento de bolhas e possibilitando maior precisão na massa que foi aferida posteriormente. Já a segunda, reforçada com as fibras, sofreu um processo de compressão por prensa hidráulica sob uma carga de 5 toneladas durante o mesmo período de tempo, para maior eficiência na impregnação das fibras de rami pela resina epóxi.

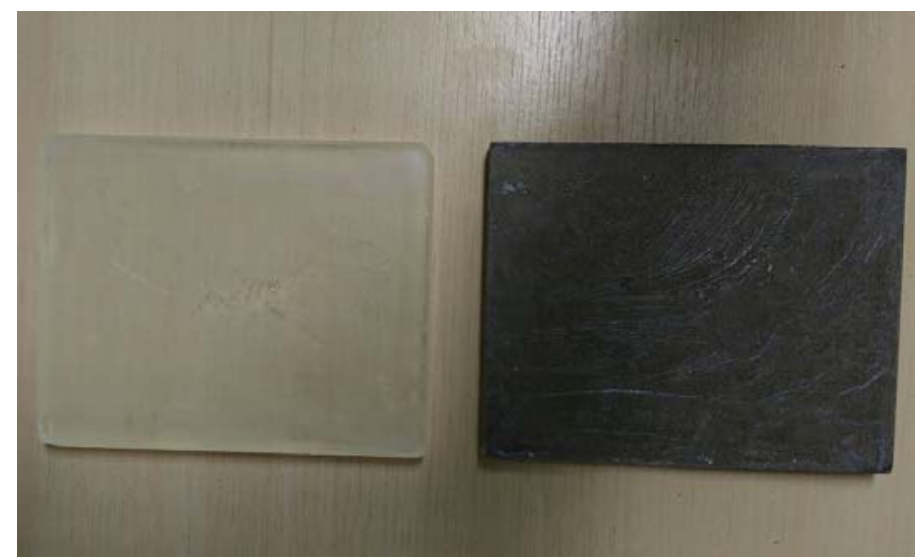

Figura 4: Placas confeccionadas para medição da densidade de tecido de rami.

O volume das placas é o mesmo e foram medidos com paquímetro. Assim, rearranjando a regra das misturas foi possível, pela variação de massa entre as placas obter um valor de densidade do tecido de rami igual à $0,93 \mathrm{~g} / \mathrm{cm}^{3}$.

Os cortes de tecido foram misturados em frações de 0,10\%, 20\% e $30 \%$ em volume com a resina, no molde, para preparar os compósitos. Após passarem pelo processo de compressão descrito anteriormente, as placas correspondentes a cada fração de tecido de rami foram cortadas em 18 peças medindo $60,25 \times 12,7 \times 10 \mathrm{~mm}$ para a confecção de corpos de prova padrão Izod de acordo com a norma ASTM D256(13). O entalhe de cada corpo de prova foi feito individualmente com uma brochadeira de 
dente único seguindo as exigências da norma: $45^{\circ}+/-1^{\circ}$ e raio de curvatura de $0,25 \mathrm{~mm}+/-0,05 \mathrm{~mm}$. Os cortes resultaram em uma espessura de $10,16 \mathrm{~mm}$ sob o entalhe.

Os ensaios de impacto Izod foram conduzidos em um pêndulo PANTEC do Instituto Militar de Engenharia. Durante os ensaios, o corpo de prova foi preso verticalmente com o entalhe centralizado e voltado para o lado onde o martelo impacta, como descreve o método A da ASTM D256. Para cada uma das peças com as dadas frações de fibra o impacto foi realizado com um martelo de 11J, a energia absorvida foi obtida e os resultados foram analisados estatisticamente.

\section{RESULTADOS E DISCUSSÃO}

Os resultados dos ensaios de impacto em termos de média e de desvio padrão da energia absorvida para cada compósito estão mostrados na Tabela 1.

Tabela 1: Energias de impacto Izod para compósitos poliéster com tecido de rami.

\begin{tabular}{|c|c|}
\hline Percentagem de tecido de Rami & Energia $(\mathrm{J} / \mathrm{m})$ \\
\hline 0 & $15,33 \pm 0,52$ \\
\hline 10 & $84,60 \pm 37,75$ \\
\hline 20 & $463,60 \pm 140,82$ \\
\hline 30 & $537,60 \pm 101,14$ \\
\hline
\end{tabular}

A variação da energia de impacto Izod com a fração em peso do tecido de rami nos compósitos está apresentada na Fig. 5. Nesta figura, observa-se que a incorporação de tecido de rami aumenta consideravelmente a tenacidade do compósito. Este aumento, dentro dos limites do desvio padrão, pode ser considerado como exponencial até o máximo de $30 \%$ de fibra. Na realidade o aumento exponencial ocorre dentro de uma extensa faixa indicada pelas linhas do gráfico da Fig 6, passando pelos limites de precisão das barras de erro.

É importante também mencionar que, com o aumento da fração da fibra, aumenta também a dispersão dos valores de tenacidade, traduzindo-se em maiores desvios padrão. Este fato é reconhecido como uma característica das fibras lignocelulósicas.

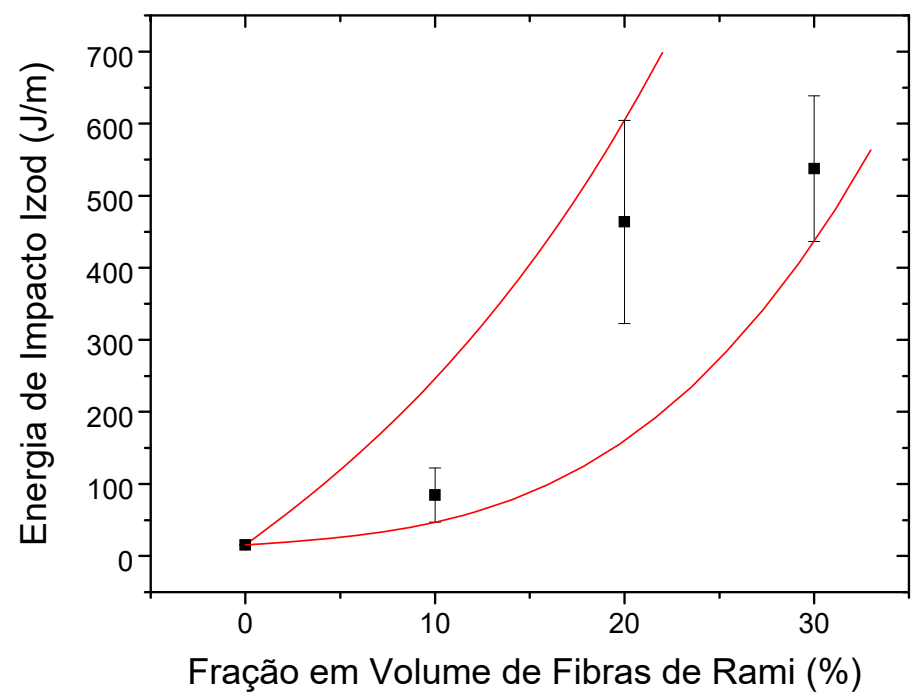

Figura 5: Variação da energia de impacto Izod com a fração de tecido de rami. 
A curva mostrada na Fig. 5 é consistente com resultados da literatura, já que o reforço de fibras, tanto sintéticas quanto naturais aumenta a tenacidade ao impacto de compósitos com matriz polimérica. A Tabela 2 apresenta valores da tenacidade ao impacto obtida em corpos de prova entalhados para compósitos de matriz polimérica reforçados com fibras naturais.

Tabela 2: Valores de tenacidade ao impacto de fibras naturais.

\begin{tabular}{c|cccc}
\hline Compósito & $\begin{array}{c}\text { Fibra } \\
\text { (\% em peso) }\end{array}$ & Martelo & $\begin{array}{c}\text { Tenacidade ao } \\
\text { Impacto }(\mathbf{J} / \mathbf{m} \text { ) }\end{array}$ & Referência \\
\hline Rami/Poliéster & 30 (continua) & Izod & 580 & Presente trabalho \\
Curauá/PP & 50 (picada) & Izod & 54 & $(16)$ \\
Madeira/PP & 50 (picada) & Izod & 28 & $(16)$ \\
Coco/PP & 50 (picada) & Izod & 46 & $(16)$ \\
Linho/PP & 50 (picada) & Izod & 38 & $(16)$ \\
Juta/PP & 50 (picada) & Izod & 39 & $(16)$ \\
Sisal/PP & 50 (picada) & Izod & 51 & $(16)$ \\
\hline
\end{tabular}

No presente trabalho, utilizando-se tecido de rami, os níveis alcançados são bem superiores aos indicados na literatura para tenacidade ao entalhe obtida por impacto Izod em compósitos com matriz de polipropileno, PP, reforçada com $50 \%$ de outras fibras. Obviamente a matriz, PP é diferente da matriz de poliéster usada no presente trabalho, porém podem dar uma idéia comparativa da maior tenacidade de compósitos, quando reforçados com tecido de rami. Em confronto com compósitos de matriz polimérica reforçados com outras fibras naturais picadas, a Tabela 2 mostra que os valores alcançados para compósitos com tecido, tanto de rami na Fig. 2 quanto de piaçava ${ }^{(23)}$, superam em muito todas as outras. A razão para este desempenho pode ser explicada através das características da fratura.

Uma baixa resistência interfacial fibra/matriz contribui para uma ineficiente transferência de esforço da matriz para a fibra, resultando assim em maior energia absorvida no impacto. Por outro lado, existe outro fator que também contribui para a maior tenacidade associada ao reforço de tecido de rami na matriz polimérica. Este fato é uma conseqüência da resistência ao dobramento destas fibras.

A Figura 3 mostra que, macroscopicamente, a incorporação de tecido de rami acarreta um comportamento marcante em relação ao poliéster puro, $0 \%$ de fibra. Mesmo com somente $10 \%$ de fibra, a área de fratura não é totalmente transversal, pois uma parte acompanha o sentido longitudinal de alinhamento das fibras. Isto indica que as trincas geradas no entalhe pelo impacto, iniciam uma propagação transversal pela matriz, como se espera em polímeros, mas ao esbarrarem nas fibras, tendem a se propagar na interface fibra/matriz. Isto está de acordo com o mecanismo de ruptura em compósitos com fraca resistência interfacial (22). Embora pareça paradoxal, uma baixa resistência interfacial acarreta em maior tenacidade, pois gera maior área de fratura e, consequentemente, maior energia absorvida no impacto.

Para frações de tecido de rami de 20 e 30\%, Fig. 6, os corpos de prova nem sequer foram rompidos no impacto. Isto se deve à elevada resistência à tração de tecido de rami, evitando a ruptura total. Para estas maiores frações de fibra, a parte não rompida do corpo de prova dobrou-se o suficiente para permitir que suas extremidades se soltassem dos batentes do equipamento. Neste caso, o resultado da energia de impacto Izod não pode ser comparado com outros em que o corpo de prova é totalmente rompido. Entretanto, a não ocorrência de ruptura no impacto 
indica uma elevada tenacidade do compósito já que, caso ocorresse a ruptura, a energia absorvida seria ainda superior.

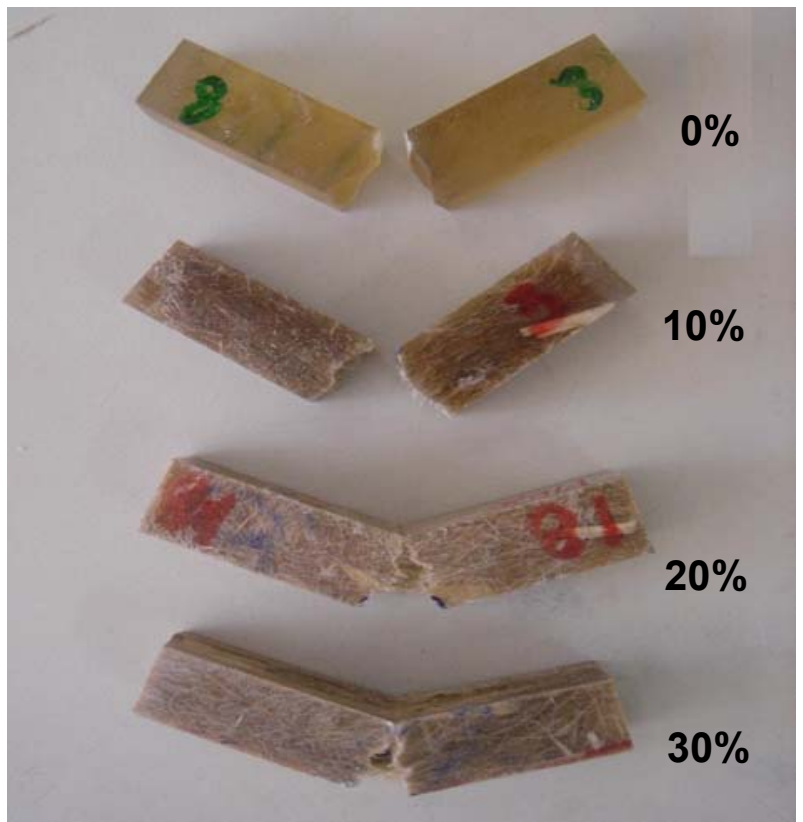

Figura 6: Aspectos macroestruturais da ruptura por impacto Izod de compósitos de matriz poliéster com diferentes frações volumétricas de tecido de rami.

A análise da microestrutura por MEV na região de fratura resultante do impacto Izod permitiu melhor compreensão dos mecanismos responsáveis pela elevada tenacidade dos compósitos reforçados com tecido de rami.

Em relação à resina pura, Fig.7, o aspecto da fratura é típico do poliéster. Com menor aumento, Fig. 7(a), tem-se uma faixa superior mais marcada e escura, correspondente ao entalhe feito pela fresa. A parte inferior, mais lisa e clara, corresponde à fratura transversal por impacto. Esta fratura, mostrada com maior aumento na Fig. 7(b), revela rugosidade associada à propagação da única trinca, nucleada no entalhe, que ocasionou a ruptura. A trinca acarretou também pequenas cavidades, provavelmente resultantes da porosidade causada pelas condições de processamento.
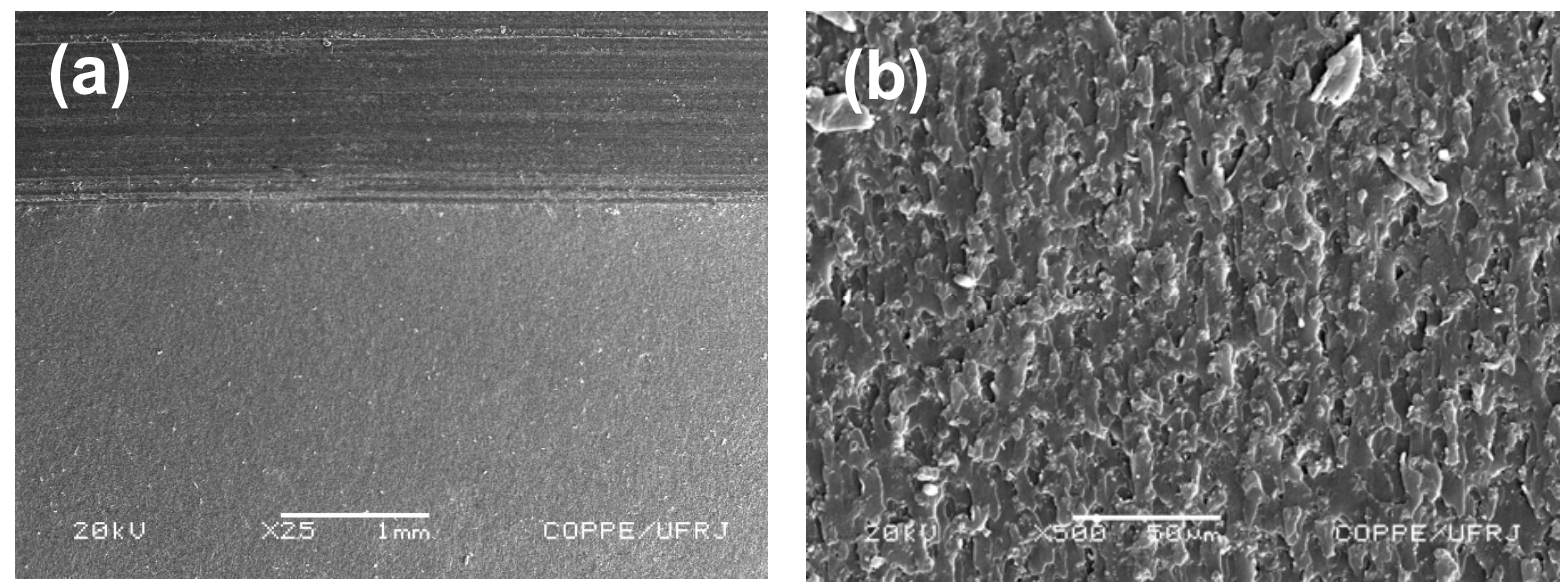

Figura 7: Fratura por impacto do corpo de prova de resina poliéster pura. (a) visão do entalhe e da superfície transversal de ruptura; (b) detalhe da ruptura. 


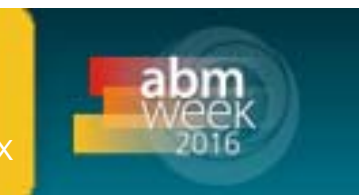

A Figura 8(a), com menor aumento, apresenta por MEV aspectos gerais da superfície rompida por impacto Izod de um corpo de prova com $30 \%$ em volume de fibras de rami reforçando matriz poliéster.
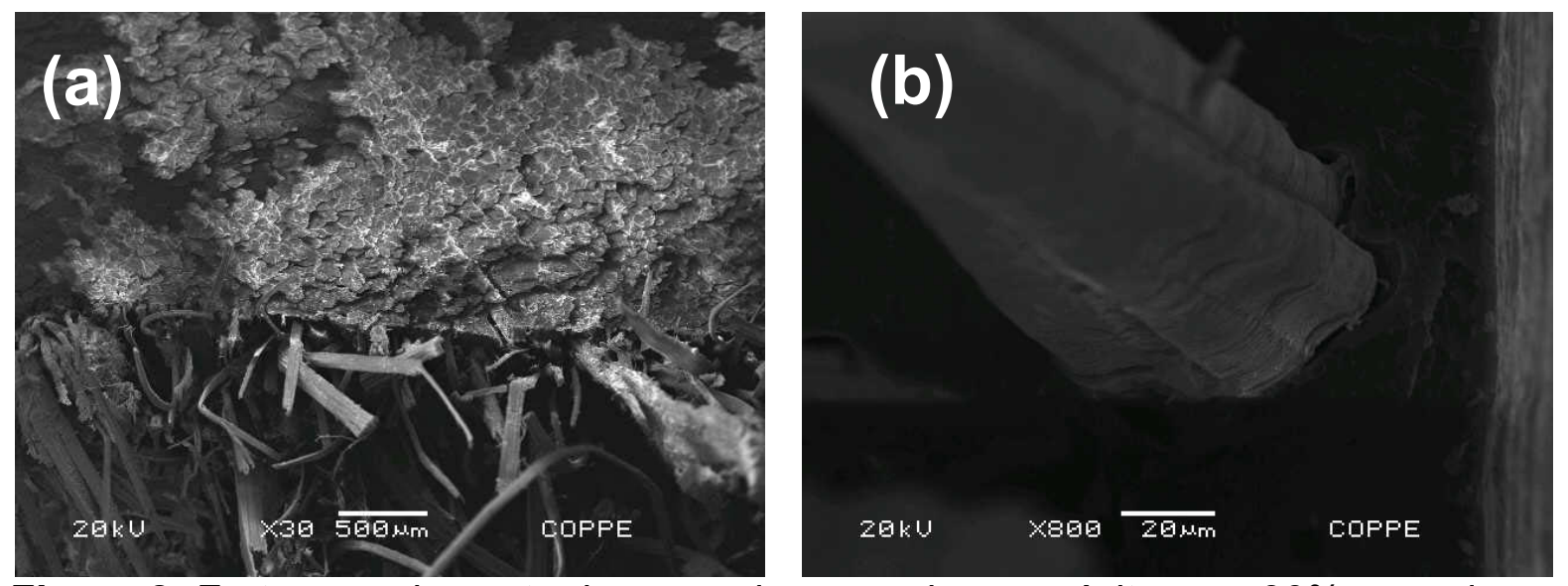

Figura 8: Fratura por impacto do corpo de prova do compósito com 30\% em volume de tecido de rami.

É importante notar que na Fig. 8(b), observada com maior aumento na região em que a fratura propagou-se seguindo a interface fibra/matriz, existem evidências de descolamento interfacial. Este comportamento corrobora o mecanismo de ruptura através de trincas que se propagam preferencialmente entre a fibra e a matriz devido à fraca resistência interfacial. A maior área longitudinal de ruptura dos compósitos como consequência do reforço do tecido de rami, justifica a elevada energia absorvida no impacto, bem como seu aumento com a fração de fibra.

\section{CONCLUSÃO}

Compósitos constituídos de tecido de rami reforçando matriz poliéster, curada à temperatura ambiente, apresentam um aumento exponencial na tenacidade ao entalhe, medida em ensaios de impacto Izod, em relação à resina poliéster pura.

Nestes compósitos, para a fração de fibra incorporada de até $30 \%$ em volume, atingem-se as mais altas tenacidades já registradas em fibras lignocelulósicas. Parte deste aumento na tenacidade é devido à baixa tensão interfacial entre o tecido de rami e a resina poliéster. Isto acarreta maior energia absorvida no impacto em decorrência da propagação de trincas na interface fibra/matriz, gerando maior área de ruptura em relação a uma fratura transversal que ocorra na matriz rompendo as fibras.

Para frações de tecido de rami superiores a $10 \%$ em volume, o aumento da tenacidade ao entalhe pode também, em parte ser devido à energia despendida em se dobrar as fibras que não são rompidas após o impacto do martelo Izod.

\section{REFERÊNCIAS}

1 MEDEIROS, M.K. Tecnologia Têxtil. Universidade Anhembi Morumbi, São Paulo, Brasil. Disponível em: http://www2.anhembi.br/html/ead01/tecnol_textil/aula1.2e3.pdf Acesso em: 07 de abril de 2016.

2 WAGNER, M.; WELLMER, F.W. Global mineral resources, occurrences and distribution. Encyclopedia of Life support Systems (EOLSS). Disponível em: 
http://www.eolss.net/sample-chapters/c09/E6-65-05-02.pdf. Acesso em 07 de abril de 2016.

3 THE ECONOMIST. A global comparison of garbage. 2012. Disponível em: http://www.economist.com/blogs/graphicdetail/2012/06/daily-chart3 ?zid=313\&ah=fe2aac0b11adef572d67aed9273b6e55\%20acessado\%20em $\% 2008 / 04 /$ 2016. Acesso em 07 de abril de 2016.

4 CAMPANHA FILHO, S. P, FROLLINI, E.; CURVELO, A.A.S. Organosolo Delignification of Ligonocellulose Materials: Preparation and Characterization of Lignin and Celulose Derivates, São Carlos: Inst de Quim -USP, 1997.

5 D. Nabi Sahed and J.P. Jog, "Natural fiber polymer composites: a review", Advances in Polymer Technol., 18 (1999), 221-274.

6 A .K. Bledzki, and J. Gassan, "Composites Reinforced With Cellulose-Based Fibers". Prog. Polym. Sci, 4 (1999) 221-274.

7 A.K. Mohanty, M. Misra and G. Hinrichsen, "Biofibers, biodegradable polymers and biocomposites: an overview", Macromolecular Mat. And Engineering, 276/277 (2000), 1-24.

8 Agência Brasileira de Desenvolvimento Industrial (ABDI). Chamada pública de seleção de estudo técnico para diagnóstico e proposição de políticas públicas no tema internet das coisas. 2016. Disponível em:

http://www.bndes.gov.br/SiteBNDES/export/sites/default/bndes pt/Galerias/Arquivos/pr odutos/download/aep_fep/chamada_internet_das_coisas_2016.pdf. Acesso e: 07 de abril de 2016.

9 Ferreira, A. da S.; Lopes, F.P.D.; Monteiro, S.N.; Satyanarayana, K.G. Charpy impact resistance of alkali treated curaua reinforced polyester composites. Revista Matéria, vol.15 no.2 Rio de Janeiro. 2010.

10 DUARTE, C.A.D, Compósitos de polipropileno reforçados com fibras de sisal para uso na indústria altomobilística. Dissertação de Mestrado. Escola Politécnica da Universidade de São Paulo (USP). São Paulo. 2010.

11 FREITAS, C.F.T.; Aspectos econômicos da cultura de rami. Disponível em: http://www.iea.sp.gov.br/ftpiea/rea/1961/asp8-61.pdf. Acesso em: 07 de abril de 2016.

12 IZOD IMPACT ENERGY OF POLYESTER MATRIX COMPOSITES REINFORCED WITH ALIGNED CURAUA FIBERS - Sergio N. Monteiro, Ailton S. Ferreira, Felipe Perissé D. Lopes

13 AMERICAN SOCIETY FOR TESTING AND MATERIALS (ASTM). ASTM D256: Standart Methods for Determining the Izod Pendulum Impact Resistance of Plastics, West Conshohocken, PA, 2010 